\title{
Status Trofik Ikan yang Berasosiasi dengan Lamun (Seagrass) di Tanjung Luar Lombok Timur
}

\author{
Oleh : \\ Abdul Syukur*1), Yusli Wardiatno ${ }^{2)}$, Ismudi Muchsin ${ }^{2)}$ \\ dan Mohammad Mukhlis Kamal ${ }^{2}$. \\ 1) Jurusan Matematikan dan Ilmu Pengetahuan Alam Program Studi Pendidikan Biologi \\ FKIP Universitas Mataram \\ 2) Departemen Manajemen Sumberdaya Perairan, Fakultas Perikanan dan Ilmu Kelautan \\ Institut Pertanian Bogor. Jl. Agatis Kampus IPB Darmaga Bogor 16680 \\ *Corespondensi author e-mail: syukur_unram@yamil.com
}

\begin{abstract}
ABSTRAK
Lamun di lingkungan laut berperan penting dalam proses pembentukan rantai makanan detritus dan herbivora. Penelitian ini bertujuan untuk menentukan status trofik ikan berdasarkan jenis makanan. Contoh ikan diambil pada lima lokasi padang lamun yaitu: Gili Kere, Gili Maringkik, Kampung Baru, Lungkak dan Poton Bakau dengan menggunakan mini pure seine. Analisis status trofik ikan dilakukan berdasarkan jenis makanan yang ditemukan pada isi lambung. Status trofik dikelompokkan dalam status trofik herbivora, carnivora, planktivora dan omnivora. Status trofik ikan yang ditemukan pada semua lokasi penelitian didominasi oleh ikan dengan status trofik carnivora sebesar 58,62 \%, status trofik herbivora sebesar 17, $64 \%$, status trofik planktivora $17,64 \%$ dan status trofik omnivora 5,88\%. Ikan yang berasosiasi dengan lamun pada lokasi penelitian sebagian besar untuk mencari makan. Namun demikian jenis ikan dari famili Apogonidae dengan spesies Archamia goni dan famili Monacanthidae dengan spesies Plectorhinchus falvomaculatus menggunakan lamun tidak hanya sebagai tempat mencari makan tetapi juga sebagai tempat untuk memijah, tinggal massa juvenil dan massa dewasa. Kesimpulan dari penelitian adalah status trofik ikan dan bentuk asosiasi ikan dengan lamun sebagai indikator fungsi ekologi lamun yang sangat vital untuk ikan dapat survive.
\end{abstract}

Kata Kunci: Lamun, Status Trofik Ikan dan Asosiasi Ikan dengan Lamun.

\begin{abstract}
Seagrass in the marine environment plays an important role in the process of detritus food chain and herbivores. This study aims to determine the trophic status of fish based on the type of food. Fish were taken on the five locations seagrass beds: Gili Kere, Gili Maringkik, Kampung Baru, Lungkak dan Poton Bakau by using pure mini seine. Analysis of trophic status of fish is done based on the type of food that is found in the stomach contents. Trophic status are grouped into trophic status of herbivores, carnivores, omnivores and planktivora. Trophic status of fish found in all study sites are dominated by carnivorous fish with trophic status of $58.62 \%$, herbivore trophic status of $17,64 \%$, trophic status planktivora $17.64 \%$ and $5.88 \%$ omnivorous trophic status. Fish associated with seagrass research sites mostly for foraging. However, the type of fish of the family Apogonidae with Archamia goni and family Monacanthidae with Plectorhinchus falvomaculatus use seagrass not only as a feeding sites but also as a place to spawning, mass live juvenile and adult the mass. The conclusion of the
\end{abstract}


study is the trophic status of fish and fish form of association with seagrass as an indicator of the ecological functions that are vital for the fish to survive.

Key Words: Seagrass, Trophic Status of Fish and Fish with Seagrass Association.

\section{PENDAHULUAN}

L

amun (seagrass) yang hidup di lingkungan laut dangkal (daerah pasang surut) merupakan objek penelitian yang akhir-akhir ini cukup berkembang terutama dari aspek ekologi yaitu tentang dinamika serta keragaman jenis biota laut seperti miofauna (nematoda dan polychaeta), makro fauna (bivalvia, amphipoda, gastropoda dan echinodermata) dan mikro fauna yaitu protozoa (Tomascik et al., 1997). Selain itu fungsi utama lamun adalah untuk stabilisasi sedimen, peningkatkan kualitas air, menentukan keseimbangan siklus gas karbon dan nutrient serta menyediakan jasa pembesaran (nursery), berlindung (shelter) dan tempat mencari makan (feeding) untuk ikan (Hemminga dan Duarte, 2000).

Padang lamun mulai diketahui memiliki nilai dari perspektif ekonomi, dimulai sejak fungsinya diketahui sebagai habitat dari banyak spesies biota laut yang bernilai ekonomi. Selain itu padang lamun dikenal memiliki produktivitas yang tinggi di lingkungan laut serta konstribsi yang besar terhadap perikanan dan bermanfaat bagi masyarakat yang tinggal di wilayah pesisir, khususnya di daerah tropis (de la Torre-Castro dan Rönnbäck, 2004). Jenis ikan yang bernilai ekonomi tinggi menggunakan lamun sebagai habitat dalam siklus hidupnya adalah jenis ikan Lutjanus monostigma dan Parupeneus barberinus, meskipun juga mengunakan mangrove dan lamun serta terumbu karang sebagai habitatnya (Honda K et al., 2013). Selanjutnya dijelaskan bahwa lebih dari $20 \%$ spesies ikan komersial menggunakan selain padang lamun sebagai habitat dalam siklus hidupnya. Dalam hal ini lamun sebagai habitat ikan ditentukan oleh kepadatan tunas (shoot density), komposisi spesies lamun, areal permukaan lamun, parameter fisika seperti arus dan gelombang dan dimana semua faktor tersebut memiliki pengaruh pada tahapan hidup ikan dan interaksinya dengan lamun (Ambo-Rappe et al., 2013)

Jasa ekosistem padang lamun terhadap ekosistem lain salah satunya dapat di nilai melalui pergerakan spesies ikan. Hal ini menunjukkan adanya kenektivitas secara ekologi antar ekosistem di wilayah pesisir. Ekosistem-ekosistem di wilayah pesisir seperti ekosistem padang lamun dalam mendukung kelimpahan ikan (fish abundant) sebagian besar dapat dijelaskan melalui sejarah dari tahapan hidup tiap spesies ikan dan instrumen ini cukup bermanfaat terutama untuk memelihara sumberdaya perikanan pesisir (Unsworth dan Cullen, 2010).

Padang lamun di perairan pesisir tropis (Indo-Pacific) menyediakan jasa yang sangat pundamental sebagai habitat keragaman jenis ikan (Nakamura et al., 2012). Secara lebih jelas tentang perbandingan kontribusi padang lamun sebagai habitat pemeliharaan (nursery ground) ikan di wilayah pesisir adalah: padang lamun dapat lebih dari $30 \%$, mangrove antara $5-10 \%$, dataran pasang surut (tidal flat) $5 \%$, rawa $25-30 \%$, terumbu karang $25 \%$ dan dasar perairan yang berlumpur lebih kecil dari $5 \%$ (Weinstein et al., 2001). Namun demikian kelimpahan dan keragaman ikan pada padang lamun perbedaan jumlah atau komposisi jenisnya atau paraiasinya pada setiap waktu tidak hanya ditentukan oleh atribut lamun tetapi juga dipengaruhi oleh kondisi hidrologi dan struktur landscape, khususnya kedalaman (Pogoreutz et al., 
2012). Oleh karena itu berkaitan dengan pola penggunaan habitat oleh tiap jenis ikan yang berbeda pada padang lamun dapat menjadi dasar dalam menjelaskan relung trofiknya atau tingkat trofiknya (Reis-Filho et al., 2011).

Jenis-jenis ikan yang sering ditemukan pada padang lamun adalah seperti famili dari Apogonidae, Blenniidae, Centriscidae, Gerreidae, Gobiidae, Labridae, Lethrinidae, Lutjanidae, Monacanthidae, Scaridae, Scorpaenidae, Siganidae, Syngnathidae dan Teraponidae (Ohman et al., 2002). Selanjutnya dijalaskan bahwa jenis ikan yang memilih lamun sebagai habitat dapat dikelompokkan berdasarkan: (1) kelompok ikan yang tinggal secara permanen, (2) kelompok ikan yang tinggal secara temporal, (3) kelompok ikan yang datang secara reguler seperti ikan karang yang migrasi secara harian (diurnally) dan (4) kelompok ikan yang datang secara sekalikali.

Ikan yang ditemukan pada areal padang lamun erat kaitannya dengan keragaman jenis makanan ikan yang ada pada padang lamun seperti: amphipoda, brachyura, stomatopoda, copepoda, polychaeta dan gastropoda dan jenis-jenis makanan ini dapat menjadi dasar untuk menilai tingkat trofik ikan (Kiswara et al., 1994). Jenis ikan berdasarkan trofiknya, dimana populasi ikan omnivora lebih dominan pada siang hari dan pada malam hari yang lebih dominan adalah kelompok dari jenis ikan pemakan invertebrata (Belt et al., 2007). Populasi-populasi ikan berdasarkan jenis trofiknya adalah faktor kunci terbentuknya rantai makanan pada padang lamun yang dapat dijelaskan melalui rantai makanan detritus dan rantai makanan herbivora (Mazzola dan Vizzini, 2004).

Areal studi adalah merupakan lokasi dengan luas areal padang lamun sebesar 154,21 ha (Syukur et al., 2012). Komposisi jenis ikan pada areal padang lamun di lokasi studi terdiri dari 42 famili, 118 spesies dan 16.049 individu dan famili ikan yang memiliki kelimpahan paling tinggi adalah Haemulidae, Mullidae dan Engraulidae (Syukur et al., 2012). Selanjutnya disebutkan bahwa nilai indek keanekaragaman ikan pada semua lokasi padang lamun berkisar antara 2,448 sampai 2,948 serta nilai indeks dominansi berkisar antara 0,077 sampai 0,164. Komposisi jenis ikan tersebut dapat menggambarkan kekayaan jenis ikan pada areal studi dan selain itu hal penting yang berkaitan dengan komposisi jenis ikan tersebut adalah tentang status trofik untuk dapat menjelaskan secara mendalam tentang peran ekologi lamun untuk ikan dapat survive.

\section{BAHAN DAN METODE}

Pengambilan contoh ikan dilakukan pada tiap lokasi padang lamun yaitu di Gili Kere, Gili Maringkik, Kampung Baru, Lungkak dan Poton Bakau dari bulan April sampai bulan Agustus 2011. Jensi alat yang digunakan adalah mini pure seine dengan spesifikasi sebagai berikut: ukuran panjang $70 \mathrm{~m}$ dengan mata jaring sayap berukuran 1,25 inci, 1 inci, 0,75 inci dan 0,625 inci serta mata jaring kantong dengan ukuran sebesar 0,5 inci. Teknik pengambilan contoh dilakukan dengan cara jaring ditarik secara tegak lurus dengan garis pantai pada tiap areal padang lamun. Selanjutnya ikan yang diperoleh pada tiap penarikan dikumpulkan pada wadah yang sudah disediakan (ember). Setelah itu ikan-ikan yang telah terkumpul dipilah sesuai dengan ciri morfologinya, kemudian dihitung jumlah individunya, diukur panjang dan ditimbang beratnya. Semua jenis ikan selanjutnya diidentifikasi menurut jenisnya berpedoman dengan kunci determinasi dari (Tsukamoto et al., 1997). 
Jenis ikan yang telah teridentifikasi selanjutnya dipilih jenis atau spesiesnya berdasarkan famili yang berbeda untuk pengambilan isi lambung yaitu untuk mengetahui jenis makanan. Jenis makanan ikan yang diperoleh selanjutnya diamati di bawah mikroskop. Jenis makanan yang diperoleh digunakan sebagai dasar untuk menganalisis dalam mengelompokkan ikan pada status trofiknya yaitu: (1) ikan omnivora $(\mathrm{O}),(2)$ ikan herbivora $(\mathrm{H}),(3)$ ikan pemakan invertebrata (1) atau (invertebrate feeder), (4) pemakan ikan dan invertebrata (IF) atau (invertebrate and fish feeder) dan (5) pemakan planktivora (P) (Bell et al. 2007).

\section{HASIL DAN PEMBAHASAN}

\section{A. Status Trofik Ikan Berdasarkan Jenis Makanan}

Jenis makanan ikan yang telah teridentifikasi berdasarkan spesies ikan berfungsi untuk menetapkan relung (niche) ekologi berdasarkan posisi trofik tiap spesies ikan. Hasil identifikasi jenis makanan ikan pada tipa spesies yang menjadi contoh yaitu jenis makanan ikan dari famili Monacantidae dengan spesies Acreichthys tomentosus, jenis makanannya adalah crustacea, ikan, larva see-urchin dan lamun dan ikan dari famili Siganidae dengan spesies Siganus canaliculatus jenis makanannya adalah lamun dan algae.

Jenis makanan dari kedua jenis ikan di atas dapat memberikan gambaran tentang: (1) kedua jenis ikan tersebut memiliki tingkat trofik yang berbeda, dimana untuk spesies Siganus canaliculatus dapat dikatagorikan sebagai ikan herbivora dan untuk spesies Acreichthys tomentosus dapat dikelompokkan pada tingkat trofik omivora dan (2) keanekaraman jenis makanan ikan yang tersedia pada lokasi padang lamun. Hal ini juga dapat menjelaskan tentang sifat fleksibilitas ikan dalam memilih jenis makanan. Famili Siganidae dari spesies
Siganus Canaliculatas jenis makanan utamanya adalah lamun tetapi juga dapat diperoleh jenis makanan lain yaitu algae (Hutomo, 1985). Perubahan jenis makanan utama dapat berubah dari jenis yang satu kejenis yang lain sejalan dengan kelimpahan atau ketersediaan jenis makanan (Supratomo, 2000). Hal ini dapat dilhat dari jenis ikan Siganus canaliculatus makanannya dapat berganti dari detritus ke daun lamun ketika berada di padang lamun, meskipun ikan ini dapat memperoleh daun laum di luar padang lamun yaitu dari daun lamun yang hanyut terbawa arus.

Jenis ikan lain yang mengalami perubahan jenis makanan adalah famili Apogonidae dari spesies Archamia goni jenis makanannya terdiri dari udang, kepiting dan cumi-cumi (Cephalophoda). Makanan ikan dari famili Apogonidae adalah udang (macrura) sebagai komponen utama dan komponen hewan (moluska dan crustacea) (Hutomo 1985) dan Supratomo (2000). Dari jenis makanan tersebut menunjukkan bahwa Apogonidae adalah kelompok ikan karnivora. Famili ikan lain dengan jenis makanan lamun dan algae adalah famili Scaridae dari spesies Calotomus spinidens dan famili Atherinidae dengan spesies Atherinomirus lacunosus. Kedua famili ini hidup di daerah pantai terutama pada daerah yang bervegetasi seperti hamparan padang lamun dan rumput laut. Selanjutnya famili Tetraodontidae dari spesies Canthigaster compressa dan Arothron immaculatus. Jenis makanan kedua spesies tersebut adalah ikan dan udang. Namun dari penelitian lain menyebutkan makanan ikan dari famili Tetraodotidae yang utama adalah hewan kecil seperti Gastropoda dan Pelecypoda yang banyak menempel pada daun lamun (Hutomo 1985). Selanjutnya dijelaskan bahwa pada kelompok spesies tersebut ditemukan lamun sebagai makanan sebesar $13,33-15 \%$ dari total jenis 
makanan.

Famili Gerridae dari spesies Gerres oyena jenis makanannya adalah ikan dan famili Mugilidae dari spesies Moolgarda delicates serta famili Pomacentridae dari spesies Abudefduf notatus. Jenis makanan dari spesies tersebut selain ikan ditemukan kaki udang, bekas kulit moluska dan potongan-potongan algae. Jenis-jenis ikan tersebut adalah juga merupakan ikan pemakan detritus meskipun bukan merupakan komponen utama tetapi selalu ditemukan pada isi lambung dan detritus tersebut adalah sisa-sisa tumbuhan dan hewan yang mati (Supratomo 2000).

Famili Mugilidae adalah kelompok ikan yang berasosiasi dengan ekosistem mangrove dan estuarin, sedangkan famili Gerreidae termasuk ikan pelagis yang terdistribusi sampai ke daerah pantai (Supratomo 2000). Famili dari Gerreidae dari spesies Gerres oyena selain memakan ikan di dalam isi lambungnya ditemukan hewan seperti copepoda dan polychaeta dalam jumlah kecil dan $67 \%$ adalah komponen hewan dan sebagain kecil pasir dan pecahan cangkang moluska (Hutomo, 1985).

Famili Haemulidae dari spesies Plectorhinchus celebicus jenis makanannya terdiri dari ikan dan kepiting (barachyura), famili Lutjanidae dengan spesies Lutjanus boutton dan Lutjanus argentimaculatus jenis makananya adalah ikan, larva ikan dan udang. Selanjutnya famili Lethrinidae dari spesies Lethrinus lentjan dan Lethrinus variegates jenis makanannya adalah kepiting. Dari jenis makanan tersebut bahwa kelompok ikan dari tiga famili tersebut dapat dikelompokkan ke dalam kelompok trofik ikan carnivora. Sisi lain pentingnya ikan dari tiga famili tersebut adalah karena sebagai ikan konsumsi yang memiliki nilai ekonomi tinggi. Famili lain yang merupakan ikan konsumsi dan bernilai ekonomi tinggi adalah famili Mullidae. Jenis makanan dari famili Mullidae dengan spesies Upeneus vittatus adalah udang.

Famili Balistidae dari spesies Balistapus undulates jenis makananya adalah larva see-urchin dan kerang, famili Balistidae jenis makanannya adalah bulu babi, kepiting, crustacea, kerang-kerangan dan tunikata. Kedua famili ikan tersebut daat dikelompokkan pada status trofik ikan karnivora. Famili ikan dari jenis Carangidae, Leiognathidae dan Clupeidae secara spesifik dari isi lambung tidak dapat diidentifikasi jenis makanannya. Namun demikian dari isi lambung merupakan bahan tercerna dan kecendungannya merupakan plankton yang terdiri dari fitoplankton dan zoopalnkton. Kelompok ikan ini cukup dominan di lokasi studi. Dua famili yaitu Carangidae dan Leiognathidae merupakan ikan yang hidup di sekitar peraian pantai dan khsusus untuk spesies dari famili Leiognathidae hidup di daerah pantai yang berlumpur. Selanjutnya famili Clupeidae adalah merupakan ikan pelagis dan masuk keperairan pantai untuk mencari makan.

Keragaman jenis makanan ikan pada padang lamun di lokasi studi adalah bentuk jasa ekologi lamun dalam menyediakan makanan untuk keragamana jenis biota laut seperti ikan. Biota laut lain sebagai makanan ikan di padang lamun dan memiliki keterkaitan dengan lamun adalah kepiting lumpur (mud crabs), see-urchin dan biota penempel (Lyimo et al., 2009). Jenis ikan (famili dan spesies) serta jenis makanannya sebagai indikator dalam menetapkan status trofik ikan pada padang lamun di lokasi studi (Tabel 1). 
Tabel 1. Famili dan spesies ikan dan jenis makanannya pada areal padang lamun di Lokasi studi

\begin{tabular}{clll}
\hline No & \multicolumn{1}{c}{ Famili } & \multicolumn{1}{c}{ Spesies } & \multicolumn{1}{c}{ Jenis makanan } \\
\hline 1 & Monacantidae & Acreichthys tomentosus & $\begin{array}{l}\text { crustacea, ikan, larva see-urchin } \\
\text { dan lamun }\end{array}$ \\
2 & Siganidae & Siganus canaliculatus & $\begin{array}{l}\text { Lamun dan algae } \\
\text { udang, kepiting dan cumi-cumi }\end{array}$ \\
3 & Apogonidae & Archamia goni & Lamun dan Alage \\
4 & Scaridae & Calotomus spinidens & Lamun dan Alage \\
5 & Atherinidae & Atherinomirus lacunosus & Ikan dan udang \\
6 & Tetraodontidae & Canthigaster compressa & Ikan dan udang \\
& & Arothron immaculatus & Ikan \\
7 & Gerridae & Gerres oyena & Ikan dan udang \\
& Mugilidae & Moolgarda delicates & Ikan dan udang \\
8 & Pomacentridae & Abudefduf notatus & ikan dan kepiting (barachyura) \\
9 & Haemulidae & Plectorhinchus celebicus & Ikan, larva ikan dan udang \\
10 & Lutjanidae & Lutjanus boutton & Ikan, larva ikan dan udang \\
& & Lutjanus argentimaculatus & Kepiting \\
11 & Lethrinidae & Lethrinus lentjan & Kepiting \\
& & Lethrinus variegates & Udang \\
12 & Mullidae & Upeneus vittatus & larva see-urchin dan kerang \\
13 & Balistidae & Balistapus undulates & Fitoplankton dan zooplankton \\
14 & Carangidae, & & Fitoplankton dan zooplankton \\
15 & Leiognathidae & & Fitoplankton dan zooplankton \\
16 & Clupeidae & Kepiting dan kerang \\
17 & Serranidae & & \\
\hline & & &
\end{tabular}

Famili dan spesies ikan serta jenis makananya (Tabel 1) memberikan informasi secara faktual bahwa padang lamun secara ekologi memiliki peran yang cukup vital sebagai areal mencari makan (feeding ground) bagi keragaman jenis ikan untuk survive. Hal lain yang cukup penting dari famili dan spesies ikan serta jenis makanannya adalah dapat diketahui relung (niche) tiap spesies ikan. Ikan yang mencari makan ke lokasi padang lamun dari semua contoh yang diperoleh didominasi oleh ikan dengan status trofik ikan carnivora yaitu sebesar 58,62 \%, ikan dengan status trofik herbivora sebesar 17, $64 \%$, ikan dengan status trofik omnivora sebesar 5,88 \% dan ikan pemakan fitoplankton dan zooplankton sebesar $17,64 \%$. Berdasarkan status trofik ikan yang ditemukan pada areal padang lamun di lokasi studi menunjukkan bahwa jenis ikan dengan status trofik herbivora memiliki ketergantungan yang sangat tinggi terhadap keberadaan lamun. Hal ini disebabkan karena jenis ikan herbivora makanan utamanya adalah lamun dan jenis alga yang berasosiasi dengan lamun. Adapun jenis ikan herbivora yang ditemukan di lokasi studi adalah Siganus canaliculatus, Calotomus spinidens dan Atherinomirus lacunosus. Hal lain yang cukup penting dari keberadaan ikan herbivora di lingkungan laut dari aspek ekologi adalah merupakan bagian utama dari salah satu rantai makanan herbivora.

\section{B. Asosiasi Ikan dengan Padang Lamun}

Ikan yang berasosiasi dengan padang lamun dapat dianalisis melalui fungsi padang lamun sebagai habitat ikan dan keanekaragaman jenis makanan ikan yang ada pada padang lamun. Ikan yang 
bermigrasi ke lokasi padang lamun sebenarnya tidak hanya untuk mencari makan tetapi juga untuk tujuan lain seperti untuk berteduh dari sengatan matahari atau untuk berlindung dari pemangsa (Bengen, 2004). Hal ini dimungkinkan karena pertumbuhan vegetasi lamun yang padat dan rimbun dapat menjadi tempat yang memadai untuk bersembunyi dari predator. Ikan yang ditemukan pada padang lamun ada yang bertujuan untuk berlindung dari predator (Mattila dan Cristoffer, 1999), dan menggunakan lamun sebagai habitat, khususnya ikan kecil (juvenil) (Asmus et $a l$. , 2005) serta areal lamun sebagai tempat ikan mencari makan menjadi indikator untuk menjelaskan migrasi ikan dari ekosistem lain ke padang lamun (Horinouchi, 2007).

Keberadaan lamun memiliki fungsi yang cukup vital dalam sikus hidup ikan terutama pada saat ikan masih muda atau massa (juvenil) terutama ikan-ikan kecil pada zona intertidal yang menggunakan lamun tempat berlindung (Hossain dan Saintilan, 2007). Oleh karena itu untuk memahami bentuk-bentuk asosiasi ikan dengan lamun dibutuhkan pengetahuan yang mendalam dan komprehensif, khususnya dalam hal keragaman bentuk manfaat ekologi sebagai habitat ikan mencari makan, berlindung dari predatator, pembesaran dan yang lainnya (Roff dan Zacharias, 2000).

Asosiasi ikan dengan lamun di lokasi studi berdasarkan indikator jenis makanan yang ditemukan pada isi lambung pada beberapa spesies ikan bentuk asosiasinya yaitu: (1) jenis ikan dari Famili Apogonidae dengan spesies Archamia goni menggunakan lamun sebagai areal mencari makan dan tempat hidup, (2) Famili Monacanthidae dengan spesies Acreichthys tomentosus adalah jenis ikan yang memanfaatkan lamun sebagai tempat mencari makan dan tempat hidup, meskipun jenis ikan ini habiatnya ada pada daerah yang dasarnya berpasir, (3) jenisjenis ikan dari beberapa famili seperti Famili Lutjanidae dengan spesies Lutjanus boutton, Famili Clupeidae dengan spesies Sardinella gibbosa, Famili Haemulidae dengan spesies Plectorhinchus falvomaculatus, Famili Leiognathidae dengan spesies Leiognathus equulus, Famili Mugilidae dengan spesies Moolgarda delicates adalah jenis ikan yang datang ke lokasi padang lamun untuk mencari makan dan (4) jenis ikan dari Famili Siganidae dengan spesies Siganus guttatus adalah merupakan ikan herbivora yang makananya lamun dan algae.

Jenis-jenis ikan yang berasosiasi dengan lamun berdasarkan bentuk asosiasinya dapat diklasifikasikan yaitu: (1) penghuni penuh yaitu yang memijah dan menghabiskan masa hidupnya di padang Iamun seperti Apogon margaritophorus, (2) penghuni yang menghabiskan hidupnya di padang lamun selama masa juvenil hingga siklus dewasa tetapi memijah di luar padang lamun seperti Halichoeres leparensis, Paramia quinquelineata, Monacanthus tomentosus, M. hajam, Hemiglyphidodon plagiumetopon dan Sygnathoides biaculeatus, (3) penghuni yang hanya pada tahap juvenil seperti Siganus canaliculatus, $S$. Virgatus, S.chrysospilos, Lethrinus spp. Scarus spp. Abudefduf spp. Monacanthus mylli dan Muloides samoensis dan (4) penghuni berkala atau transit yaitu untuk berlindung dan mencari makan (Tomascik at al., 1997).

\section{SIMPUAN}

Famili dan spesies ikan serta jenis makananya memberikan informasi secara faktual tentang relung (niche) tiap spesies ikan. Status trofik ikan di lokasi studi didominasi oleh status trofik ikan 
carnivora, selanjutnya adalah dengan status trofik herbivora dan planktivora dan yang paling kecil adalah ikan dengan status trofik omnivora. Jenis-jenis ikan yang ditemukan pada padang lamun sebagian besar memanfaatkan lamun sebagai areal mencari makan dan sebagian kecil jenis ikan yang menggunakan lamun sebagai habitat dari semua siklus hidupnya seperti memijah, massa juvenil dan dewasa.

\section{DAFTAR PUSTAKA}

Ambo-Rappe, R., M. N. Nessa, H. Latuconsina dan D. L. Lajus. 2013. Relationship between the tropical seagrass bed characteristics and the structure of the associated fish community. Open Journal of Ecology., 3 (5): 331-342.

Asmus, H., P. Polte dan S. Schanz. 2005. The contribution of seagrass beds (Zostera noltii) to the function of tidal flats as a juvenile habitat for dominant, mobile epibenthos in the Wadden Sea. Marine Biology., 147: $813-822$.

Bell, J. J, R.K.F. Unwort, E. Wyle dan O.J. Smith. 2007. Diel troflk of seagrass fish assemblages in the Wakatobi Marine National Park, Indonesia. Estuarine Coastal and Shelf Science., $81-88$.

Bengen, D. G. 2004. Ekosistem Pesisir dan Laut. Sinopsis. Pusat Kajian Sumberdaya Pesisir dan Laut IPB. Bogor.

de la Torre-Castro, M. dan P. Rönnbäck. 2004. Links between humans and seagrasses an example from tropical East Africa. Ocean and Coastal Management., 47: 361-387.

Engeman, R.M. 2008. Assessing boat damage to seagrass bed habitat in a Florida Park from a bioeconomics perspective. Coastal Research., 24: $527-532$.

Hemminga, M. A dan C. M. Duarte. 2000. Seagrass Ecology. Cambridge University Press. New York.

Honda, K., Y. Nakamura, M. Nakaoka1, H. U. Wilfredo dan M. D. Fortes. 2013. Habitat Use by Fishes in Coral Reefs, Seagrass Beds and Mangrove Habitats in the Philippines. PLOS ONE., 8: 1-10.

Horinouchi, M. 2007. Distribusi patterns of benthic juvenile gobies in and around seagrass habitat: Effectiveness of seagrass shelter against predators. Estuarine, Coastal and Shelf Science., 72: 657 - 664 .

Hossain, K., dan N. Saintilan. 2007. Lingkages between seagrass, mangrove and saltmarsh as fish habitat in the Botany Bay estuary, New South Wales. Wetlands Ecol Manage., 15: 277 - 286.

Hutomo, M. 1985. Telaah Ekologik Komunitas Ikan Pada Padang Lamun (Seagrass, Anthophyta) di Perairan Teluk Banten. Disertasi. Pasca Sarjana IPB. Bogor.

Kiswara, W., M.K. Moosa dan M. Hutomo. 1994. Struktur Komunitas Lamun di Pantai Selatan Lombok dan Kondisi Lingkungannya. Pusat Penelitian dan Pengembangan Oseanologi LIPI: 15 - 33.

Lyimo, F. Mamboya, L. Lugomela, E. Mvungi, M.Hamisi M, A.T.Kamukuru dan J.Thomas . 2009. Seagrass-sea-urchin interaction in shallow littoral zone of Dar es Salaam, Tanzania. Aqutic Conservation: Marine and Freshwater Ecosystems., 19: 19 - 26. 
Mazzola, A., dan S. Vizzini. 2004. The trophic structure of the pipefish community (Pisces: Syngnathidae) from a Western Mediterranean seagrass meadow based on stable isotope analysis. Estuarin., 27 (2): $325-333$.

Mattila, J., dan Bostrom C. 1999. The relative importance of food and shelter for seagrass-associated invertebrates: a latitudinal comparason of habitat chois by isopod grazers. Oecologia., 120: 162 -172 .

Nakamura, Y., K Hirota, T Shibuno and Y Watanabe. 2012. Variability in nursery function of tropical seagrass beds during fish ontogeny: timing of ontogenetic habitat shift. Mar Biol. 159:1305-1315.

Reis-Filho, J.A., F. Barros, J.D.A.C.D.C. Nunes, C.L.S. Sampaio, G.B.G. De Souza. 2011. Moon and tide effects on fish capture in a tropical tidal flat. $J$ Mar Biol Ass UK ., 91:735-743.

Roff, J, G., dan M.A. Zacharias . 2000. A hierarchical ecological approach to conserving marine biodiversity. Conserving Marine Biodiversity., $1327-1333$.

Supratomo, R. T. 2000. Fungsi padang lamun (seagrass) sebagai area mencari makan dengan indikator migrasi ikan terumbu karang. Tesis. Pasca Sarjana IPB. Bogor.

Syukur, A., Y.Wardiatno, I.Muchsin dan
M.M. Kamal. 2012. Desain konservasi lamun untuk keberlanjutan sumberdaya ikan di Tanjung Luar Lombok Timur. Disertasi Pascasarjana Institut Pertanian Bogor. IPB

Syukur, A., Y. Wardiatno, I. Muksain dan M.M. Kamal. 2012. Keragaman jenis ikan pada padang lamun di Tanjung Luar Lombok Timur. Biotrofis FKIP Unram., 13 (1): 125-136.

Tomascik, T., A. J. Mah, A. Nontji dan M. K. Moosa. 1997. The Ecology of the Indonesien seas. P. In the Republic of Singapore.

Tsukamoto, K., M, Keiichi dan S.O.Kurnaen. 1997. Fiel Guide to Lombok Island: Identification Guide to Marine Organisms In Seagrass Beds Lombok Island. Ocean Research Institut University of Tokyo pp. 445.

Unsworth, R. K. F., dan L.C. Cullen. 2010. Recognising the necessity for Indo-Pacific seagrass conservation. Mini-Review. Conservation Letter. 1 -11 .

Weinstein, M.P., W.B.K.L.Michael, J.R. Heck, W.A.Kenneth, L.C.Daniel, B.E. David, M.G. Bronwyn, H. Benjamin, G.H. Cynthia, H. Kaho, J,M. Thomas, J.O. Robert dan F.S. Peter. 2001. The identification, conservation, and management of estuarine and marine nurseries for fish and invertebrates. Bio-Science., 51: $663-641$ 